\title{
The Study on Influence of the Method of Handling of Measuring Head on Measurement Results Obtained with the Use of a Portable Profilometer
}

\author{
Krzysztof STĘPIEŃ, Stefan TALU
}

\begin{abstract}
Portable profilometers are very common in industrial practice. In particular, they are useful if one wants to perform in-situ inspection of surface roughness under industrial conditions. They are usually small and light and owing to that they are portable and this is why they can be applied under industrial conditions. However, there are numerous factors that influence results of in-situ surface roughness measurements. One of such factors is a human error, since the measuring head is usually controlled manually by an operator. The paper presents results of the research aiming at establishing if there is statistically significant difference between results obtained for mechanical or manual handling of measuring head. In the experiments the following parameters were analyzed: $R a, R q, R t$ and $R S m$.
\end{abstract}

Keywords: error; manual handling; portable profilometer

\section{INTRODUCTION}

Growing competition that is at present observed in the market of goods and services affects the area of manufacturing of mechanical parts and devices [1]. Such competition requires manufacturing more and more reliable products. In order to obtain this goal the manufactured parts should be of very high quality [2]. It associates with increasing demands of the high geometrical accuracy of elements. Geometrical accuracy is not only dimensional accuracy. It relates also to high quality of surface texture of elements, which includes: form errors, waviness and roughness [3-5].

Surfaces of mechanical parts are not ideally smooth since they are affected by a number of various factors, such as: vibrations, cutting tool wear, errors of machine tools guideways, etc. [6].

The subject of measurements of surface texture is very complex. Thus, various aspects of this problem are studied by a number of researchers. Some of them deal with the influence of cutting parameters on surface texture of machined elements [7]. Another area under investigation is development of new methods of evaluation of surface roughness parameters [8]. Efforts are undertaken also to seek new methods of measurement of surface roughness [9]. A very important field of study is development of new methods of surface filtering [10-12].

Generally, surface texture of machine parts is evaluated quantitatively with the use of parameters such as $P a, R a, W a$ and similar [13]. Qualitative assessment of the surface texture is usually performed through a graphical representation of irregularities in different types of diagrams. Sometimes an additional analysis of the surface is useful, which is based on digital signal processing methods [14, 15]. Among methods of digital signal processing the Fourier analysis is the most common method [16, 17]. However, also other methods are at present applied more and more often to analyze surface irregularities, for example wavelet transform [18].

Generally, instruments for surface roughness measurements can be divided into two main groups: stationary profilometers and portable ones. This paper deals with the problem of the measurement accuracy of portable profilometers.
They are instruments that can be applied to in-situ surface roughness measurements $[19,20]$. Portable profilometers are usually contact ones. Usually they are equipped with a capacitance, piezoelectric or inductive transducer. They are usually small and light and owing to that they are portable and this is why they can be applied under industrial conditions. However, there are numerous factors that influence results of in-situ surface roughness measurements. One of such factors is a human error, since the measuring head is usually controlled manually by an operator. This is the reason why the research was initiated that aimed at establishing if there is a statistically significant difference between results obtained when the measuring head was held manually and mechanically during measurements.

\section{PLAN OF THE EXPERIMENT}

The experimental research aimed at statistical evaluation of differences between results obtained when the head of the instrument was handled manually and mechanically. The instrument used in the experiment was a typical portable profilometer, commonly applied in industry. The measuring tip of the instrument was equipped with a skid. The instrument allows users to conduct measurements quite quickly and easily. Its software makes it possible to determine all roughness parameters defined by the standard ISO 4297.

The specimen was a surface of a sinusoidal roughness standard, whose nominal value of parameter Ra was equal to $0,97 \mu \mathrm{m}$. The experiment included conducting of one hundred of measurements. Fifty of them were carried out when the head was held manually by the operator. The other fifty measurements were performed when the measuring head was fixed mechanically to the column of the instrument. During the measurements the following roughness parameters were determined: $R a, R q, R t$ and $R S m$. For each investigated parameter the following analysis was performed:

- Calculation of mean values, standard deviations and ranges for both measurement series. After calculations we obtain the following parameters:

$\bar{x}_{1}-$ mean value of the parameter $R a$ from the first series of measurements, 
$\bar{x}_{2}-$ mean value of the parameter Ra from the second series of measurements,

$s_{1}$ - mean square deviation of the measurement results in the first series of measurements,

$s_{2}$ - mean square deviation of the measurement results in the second series of measurements,

$R_{1}$ - the range of the measurement results in the first series of measurements,

$R_{2}$ - the range of the measurement results in the second series of measurements.

- Comparison of mean values $\bar{x}_{1}$ and $\bar{x}_{2}$ by the statistical test aiming at an evaluation if the difference between them is statistically significant. The test was conducted with use of the following equation:

$$
t=\frac{\bar{x}_{1}-\bar{x}_{2}}{\sqrt{\frac{s_{1}^{2}+s_{2}^{2}}{n}}}
$$

where $n$ is the number of measurements in each series. (in the experiment $n=50$ ). Assumed level of significance for the test is 0.05 . The critical value of quantity $t$ for this significance level was equal to $t_{\alpha}=1,645$.

\section{RESULTS}

The experiment resulted in obtaining two sets of fifty values for each investigated parameter. These couples of sets of values were then analyzed according to the procedure given in the previous section.

\subsection{Parameter $R a$}

Diagram shown in Fig. 1 presents results of measurements of parameter $R a$ obtained during the experiment.

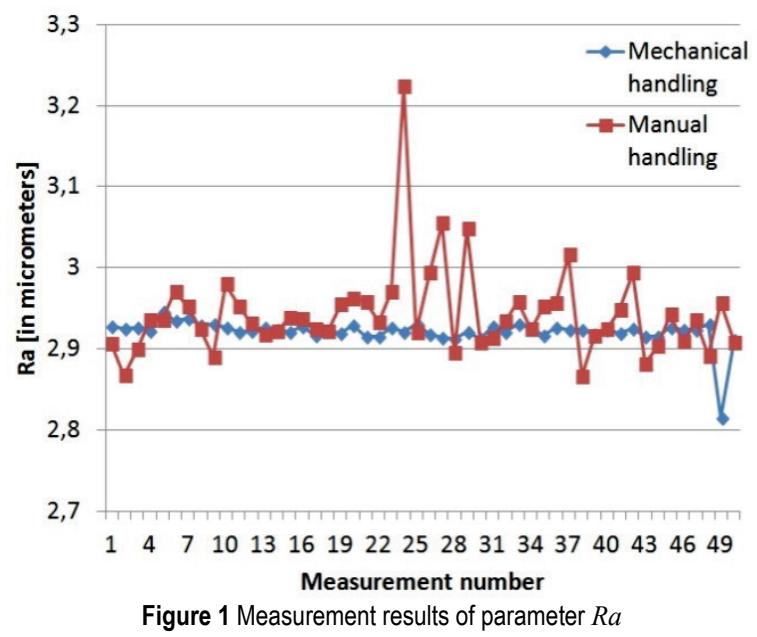

For the results of both measurement series the following statistical parameters were calculated: arithmetic mean, mean square deviation, maximum value, minimum value and range. Values of determined parameters are given in Tab. 1 .

Value of the quantity $t$, calculated from the Eq. (1) for the results of both measurement series was equal to 2,886 . This is the value higher than critical one that equals 1,645 for assumed probability level $P=0,95$. Thus, according to this test the difference between arithmetic means of $\mathrm{Ra}$ is statistically significant.

Table 1 Statistical parameters calculated measurement results of $R a$

\begin{tabular}{|l|c|c|}
\hline Name of the parameter & $\begin{array}{c}\text { Manual } \\
\text { handling } \\
(\mu \mathrm{m})\end{array}$ & $\begin{array}{c}\text { Mechanical } \\
\text { handling } \\
(\mu \mathrm{m})\end{array}$ \\
\hline Arithmetic mean & 2,94 & 2,92 \\
\hline Mean square deviation & 0,06 & 0,02 \\
\hline Maximum value & 3,22 & 2,95 \\
\hline Minimum value & 2,87 & 2,81 \\
\hline Range & 0,36 & 0,13 \\
\hline
\end{tabular}

\subsection{Parameter $R q$}

Diagram shown in Fig. 2 presents results of measurements of parameter $R q$ obtained during the experiment.

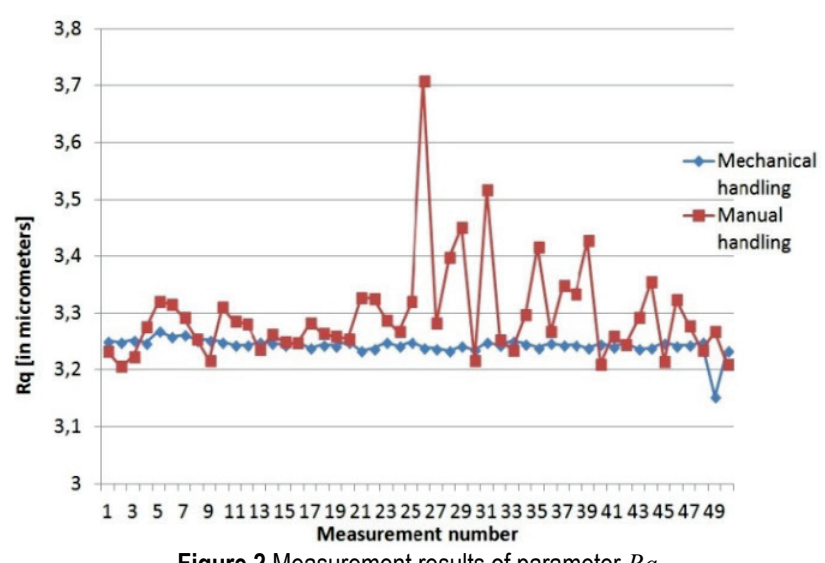

Figure 2 Measurement results of parameter $R q$

Values of statistical parameters calculated for both measurement series are given in Tab. 2 .

Table 2 Statistical parameters calculated measurement results of $R q$

\begin{tabular}{|l|c|c|}
\hline \multicolumn{1}{|c|}{ Name of the parameter } & $\begin{array}{c}\text { Manual } \\
\text { handling } \\
(\mu \mathrm{m})\end{array}$ & $\begin{array}{c}\text { Mechanical } \\
\text { handling } \\
(\mu \mathrm{m})\end{array}$ \\
\hline Arithmetic mean & 3,30 & 3,24 \\
\hline Mean square deviation & 0,09 & 0,01 \\
\hline Maximum value & 3,71 & 3,27 \\
\hline Minimum value & 3,21 & 3,15 \\
\hline Range & 0,5 & 0,11 \\
\hline
\end{tabular}

Value of the quantity $t$, calculated from the Eq. (1) for the results of both measurement series was equal to 4,301 . This is the value higher than the critical one that equals 1,645 for assumed probability level $P=0,95$. Thus, according to this test the difference between arithmetic means of $R q$ is statistically significant.

\subsection{Parameter $R t$}

Diagram shown in Fig. 3 presents the results of measurements of parameter Rt obtained during the experiment.

Values of statistical parameters calculated for both measurement series are given in Tab. 3 . 


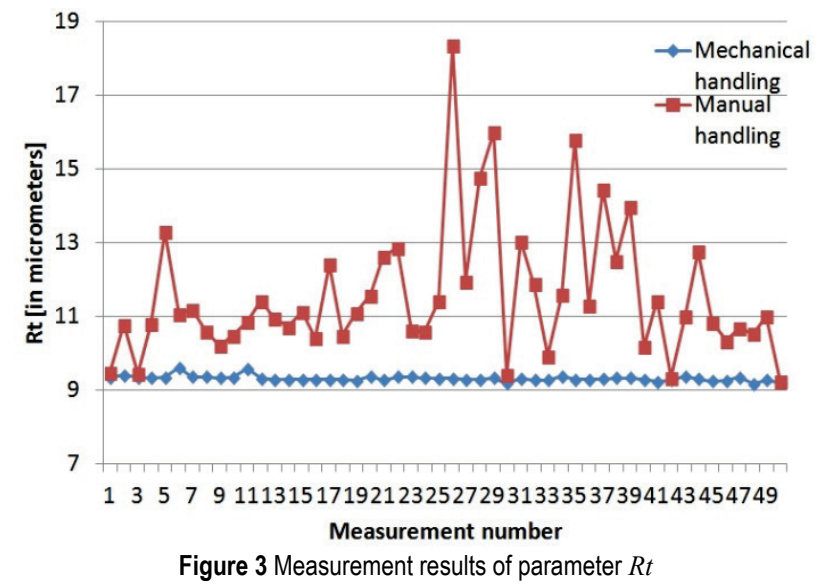

Table 3 Statistical parameters calculated measurement results of $R t$

\begin{tabular}{|l|c|c|}
\hline \multicolumn{1}{|c|}{ Name of the parameter } & $\begin{array}{c}\text { Manual } \\
\text { handling } \\
(\mu \mathrm{m})\end{array}$ & $\begin{array}{c}\text { Mechanical } \\
\text { handling } \\
(\mu \mathrm{m})\end{array}$ \\
\hline Arithmetic mean & 11,58 & 9,32 \\
\hline Mean square deviation & 1,83 & 0,07 \\
\hline Maximum value & 18,37 & 9,61 \\
\hline Minimum value & 9,24 & 9,17 \\
\hline Range & 9,12 & 0,44 \\
\hline
\end{tabular}

Value of the quantity $t$, calculated from the Eq. (1) for the results of both measurement series was equal to 8,740 . This is the value higher than the critical one that equals 1,645 for assumed probability level $P=0,95$. Thus, according to this test the difference between arithmetic means of $R t$ is statistically significant.

\subsection{Parameter $R S m$}

Diagram shown in Fig. 4 presents the results of measurements of parameter $R S m$ obtained during the experiment.

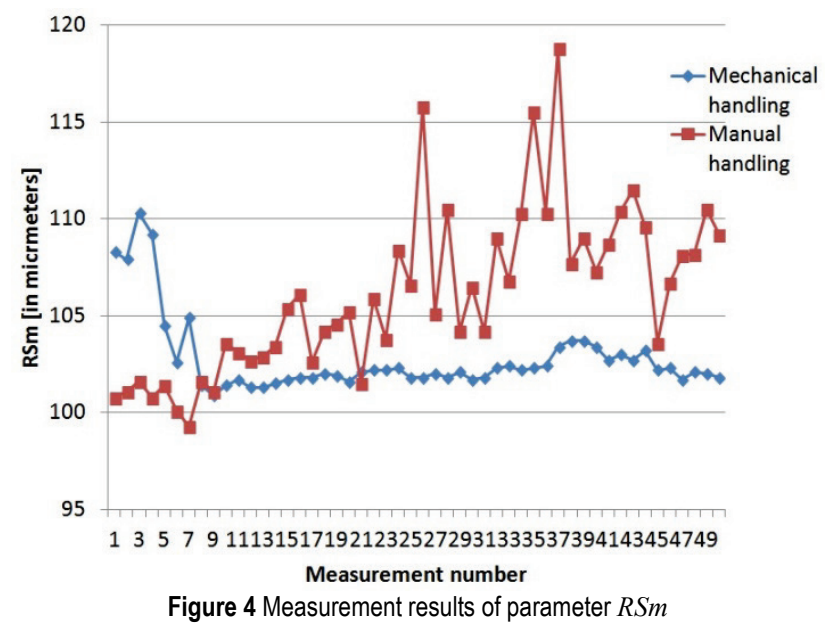

Values of statistical parameters calculated for both measurement series are given in Tab. 4.

Value of the quantity $t$, calculated from the Eq. (1) for the results of both measurement series was equal to 6,264 . This is the value higher than the critical one that equals 1,645 for assumed probability level $P=0,95$. Thus, according to this test the difference between arithmetic means of $R S m$ is statistically significant.
Table 4 Statistical parameters calculated measurement results of $R S m$

\begin{tabular}{|l|c|c|}
\hline Name of the parameter & $\begin{array}{c}\text { Manual } \\
\text { handling } \\
(\mu \mathrm{m})\end{array}$ & $\begin{array}{c}\text { Mechanical } \\
\text { handling } \\
(\mu \mathrm{m})\end{array}$ \\
\hline Arithmetic mean & 106,11 & 102,79 \\
\hline Mean square deviation & 4,25 & 2,01 \\
\hline Maximum value & 118,8 & 110,3 \\
\hline Minimum value & 99,3 & 100,9 \\
\hline Range & 19,5 & 9,4 \\
\hline
\end{tabular}

\section{CONCLUSIONS}

Analysis of the results of the experiment shows that manual handling of the measuring head can influence measurement results. Diagrams presented in Figs. 1-4 show that measurements results obtained when the head was held manually diverse more than the ones obtained when the head was fixed to the column of the instrument. This observation can be confirmed by the analysis of numerical values of statistical parameters given in Tabs. 14. It is easy to notice that values of mean square deviation and the range are much higher for manual handling than for mechanical handling.

It is also clear that the way of handling influences values of all analyzed roughness parameters. However, this influence is strongest in the case of parameter Rt. Other parameters, i.e. $R a, R q$ and $R S m$ are a little less sensitive for the method of handling of the head, because they are calculated as arithmetic or square means. Nevertheless, the result of the test of difference between mean values of all analyzed roughness parameters proves that the difference is statistically significant. Thus, users of portable profilometers should be conscious of the fact that the manual handling of the measuring head can be the reason of significant measurement errors.

\section{Acknowledgements}

The paper has been elaborated within the framework of the research project entitled "Theoretical and experimental problems of integrated 3D measurements of elements' surfaces", reg. no.: 2015/19/B/ST8/02643, ID: 317012, financed by National Science Centre, Poland.

Some results given in this paper were presented at the $5^{\text {th }}$ International Conference on Surface Metrology, $4^{\text {th }}-7^{\text {th }}$ April 2016, Poznan University of Technology, Poland.

\section{REFERENCES}

[1] Janusiewicz, A. et al. (2011). Determining the theoretical method error during an on-machine roundness measurement. Measurement, 44(9), 1761-1767.

https://doi.org/10.1016/j.measurement.2011.07.013

[2] Jermak, C. J. \& Rucki, M. (2016). Static Characteristics of Air Gauges Applied in the Roundness Assessment. Metrology and Measurement Systems, 23(1), 85-96. https://doi.org/10.1515/mms-2016-0009

[3] Zorawski, W. et al. (2015). Microstructure and tribological properties of nanostructured and conventional plasma sprayed alumina-titania coatings. Surface \& Coatings Technology, 268, 190-197. https://doi.org/10.1016/j.surfcoat.2014.09.014

[4] Kundera, C. \& Kozior, T. (2014). Research of the elastic properties of bellows made in SLS technology. Advanced Materials Research, 874, 77-81. 
https://doi.org/10.4028/www.scientific.net/AMR.874.77

[5] Poniatowska M. (2009). Research on spatial interrelations of geometric deviations determined in coordinate measurements of free-form surfaces. Metrology and Measurement Systems, 16(3), 501-510.

[6] Humienny, Z. \& Turek, P. (2012). Animated visualization of the maximum material requirement. Measurement, 45(10), 2283-2287. https://doi.org/10.1016/j.measurement.2011.09.018

[7] Adamczak, S., Miko, E., \& Cus, F. (2009). A model of surface roughness constitution in the metal cutting process applying tools with defined stereometry. Strojniski VestnikJournal of Mechanical Engineering, 55, 45-54.

[8] Zawada-Tomkiewicz, A. (2010). Estimation of surface roughness parameter based on machined surface image. Metrology and Measurement Systems, 17(3), 493-504. https://doi.org/10.2478/v10178-010-0041-5

[9] Quinsat, Y. \& Tournier, Ch. (2012). In situ non-contact measurements of surface roughness. Precision Engineering, 36(1), 97-103. https://doi.org/10.1016/j.precisioneng.2011.07.011

[10] Pawlus, P. (2007). Digitisation of surface topography measurement results. Measurement, 40(6), 672-686. https://doi.org/10.1016/j.measurement.2006.07.009

[11] Janecki, D. (2011). Gaussian filters with profile extrapolation. Precision Engineering, 35(4), 602-606. https://doi.org/10.1016/j.precisioneng.2011.04.003

[12] Janecki, D. (2009). A generalized L2-spline filter. Measurement, 42(6), 937-943. https://doi.org/10.1016/j.measurement.2009.01.020

[13] Mathia, T. G. et al. (2011). Recent trends in surface metrology. Wear, 271(3-4), 494-508. https://doi.org/10.1016/j.wear.2010.06.001

[14] Marteau, J. \& Bigerelle, M. (2015). Relation between surface hardening and roughness induced by ultrasonic shot peening. Tribology International, 83, 105-113. https://doi.org/10.1016/j.triboint.2014.11.006

[15] Lipiński，D., Kacalak, W., \& Tomkowski， R. (2014). Methodology of evaluation of abrasive tool wear with the use of laser scanning microscopy. Scanning, 36(1), 53-63. https://doi.org/10.1002/sca.21088

[16] Głowacz, A., Głowacz, W., \& Głowacz, Z. (2015). Recognition of armature current of DC generator depending on rotor speed using FFT, MSAF-1 and LDA. Eksploatacja $i$ Niezawodnosc - Maintenance and Reliability, 17(1), 64-69. https://doi.org/10.17531/ein.2015.1.9

[17] Głowacz, A. (2014). Diagnostics of DC and Induction Motors Based on the Analysis of Acoustic Signals. Measurement Science Review, 14(4), 257-262. https://doi.org/10.2478/msr-2014-0035

[18] Khoma, A. \& Zygarlicki, J. (2015). Surface topology reconstruction from the white light interferogram by means of prony analysis. Metrology and Measurement Systems, 22(4), 479-490. https://doi.org/10.1515/mms-2015-0049

[19] Stępień, K. (2012). Statistical testing of the measurement accuracy of mobile roughness measuring instruments. Proceedings of the XX IMEKO World Congress, Metrology for Green Growth, September 9 - 14 / Busan, South Korea.

[20] Stępień, K. (2015). Testing the accuracy of surface roughness measurements carried out with a portable profilometer. Key Engineering Materials, 637, 69-73. https://doi.org/10.4028/www.scientific.net/KEM.637.69

\section{Contact information:}

Krzysztof STEPIEŃ, Prof. PhD

Kielce University of Technology,

Al. 1000-lecia P. P. 7, 25-314 Kielce, Poland

E-mail: kstepien@tu.kielce.pl

Stefan TALU, Assoc. Prof. PhD

Technical University of Cluj-Napoca,

Faculty of Mechanical Engineering,

Department of AET,

Discipline of Descriptive Geometry and Engineering Graphics, 103-105 B-dul Muncii St., Cluj-Napoca 400641, Cluj, Romania 